\title{
Periodontal Barrier Membranes: A Review with Case Report
}

\author{
K.K. Gupta*, Amitabh Srivastava, Vinod Kumar and Snehi Kumar \\ Department of Periodontology, Sardar Patel Postgraduate Institute of Dental and Medical Sciences, \\ Lucknow, Uttar Pradesh, India
}

\begin{abstract}
Periodontal regeneration is healing after periodontal surgery that results in the formation of new attachment apparatus, consisting of cementum,periodontal ligament(PDL) and alveolar bone. Although the goal of complete and predictable regeneration still remains elusive, many techniques and materials have been developed that show good clinical and histologic outcomes. Advancements in periodontal regenerative armamentarium have encouraged clinicians to aggressively seek this therapeutic goal. Guided tissue regeneration (GTR) is effective in halting tissue and bone destruction and promoting new tissue and bone formation. Reconstructive dental professionals are constantly looking for an edge that jump starts the healing process to maximize predictability as well as quality and quantity of regenerated bone.
\end{abstract}

Keywords: Barrier membranes, guided tissue regeneration, periodontal defect, Platelet Rich Fibrin (PRF), bone graft.

\section{INTRODUCTION}

The aging population is one of the main reasons we need to advance the understanding of dental biomaterials. There has been a considerable increase in the number of surgical and restorative procedures related to either oral rehabilitation with the placement of dental implants and ceramic crowns or to periodontal regeneration, which often requires the use of membranes for guided tissue/bone regeneration (GTR/GBR) and grafting materials [1]. Periodontal diseases leading to deterioration of tooth-supporting structures are a serious concern for clinicians. Treatment of large bone defects represents a great challenge in orthopedic and cranio-maxillo-facial surgery. Although there are several methods for bone reconstruction, they all have specific indications and limitations. The concept of using barrier membranes for restoration of bone defects has been developed in an effort to simplify their treatment by offering a singlestaged procedure. Spatially-directed regeneration of periodontal tissues through manipulation of cell fate pathways is referred to as guided tissue regeneration (GTR) [2]. Guided tissue regeneration (GTR) is defined as procedures attempting to regenerate lost periodontal structures through differential tissue responses.

The idea of following nature's strategies to regenerate periodontal tissues goes back to Bernhard Gottlieb, who almost 6 decades ago suggested that "if these ideas about the biology of the cementum are correct, it is then our task to find out just how nature provides for continuous cementum deposition, and

*Address correspondence to this author at the Department of Periodontology, Sardar Patel Postgraduate Institute of Dental and Medical Sciences, Chaudhary Vihar, Uthrathia, Lucknow, Uttar Pradesh, India; Tel: 9450464989; Fax: 05222440335; E-mail: drkkgupta26@gmail.com having done so, to imitate the procedure". Another milestone in the science of periodontal regeneration was the work of Tony Melcher, who proposed that the PDL contains the progenitors for the regeneration of all 3 tissues, PDL, alveolar bone, and root cementum. He believed that although the PDL had lesser regenerative qualities than alveolar bone, the seemless integration of mineralized and soft tissues would be promoted by using ligament cells as progenitors, a strategy that would be further facilitated by the lack of a periosteal covering of alveolar bone and the potential for seemless integration.

Melcher's work established the biological foundation for the pioneering studies of Sture Nyman, Thorkild Karring, Jan Gottlow, and Jan Lindhe related to guided tissue regeneration. In these studies, a Millipore filter was used to prevent the gingival tissue from contact with the root surface and to allow the PDL cells to reestablish connective tissue attachment [3]. During the 1980 's and 1990's, a large volume of investigation into guided tissue regeneration (GTR) using membranes established its effectiveness in treating the specific periodontitis-induced resorptive defects, particularly vis-à-vis other surgical and non-surgical modalities [4]. By 1986, Gottlow et al. coined the term guided tissue regeneration (GTR) to describe this treatment modality which allows for the formation of bone, cementum and PDL in degranulated periodontal defects [5].

The initial hypothesis was that different cellular components in the tissue have varying rates of migration into a wound area during healing and that a mechanical hindrance would exclude the invasion of inhibiting substances, such as fibroblasts and epithelial cells. In the GTR principle, barrier porosity allows free 
movement of nutrients but not cells [6]. The regeneration process occurring within the barrier membrane involves angiogenesis and migration of osteogenic cells from the periphery towards the center to create a well-vascularized granulation tissue. Initial organization of the blood clot is followed by vascular ingrowth and woven bone deposition, subsequent lamellar bone formation and finally remodeling, resembling bone growth.

However, in large defects, bone formation occurs only to the marginal stable zone with a central zone of disorganized loose connective tissue, and, therefore, additional use of bone-graft materials is required in these cases, with the graft acting as a scaffold for osteoconduction and as a source of osteogenic and osteoinductive substances for lamellar bone formation. To help promote tissue /bone regeneration and healing, the local application of growth factors/cytokines and host modulating agents are also being used to maximize the body's healing potential. Growth factors and hormones including platelet-rich plasma (PRP), bone morphogenic proteins (BMPs), platelet-derived growth factor (PDGF), parathyroid hormone (PTH), and enamel matrix proteins (EMD) have shown promising results in enhancing regeneration, although their longterm predictability remains questionable, and their anticipated benefits are moderate [7].

Guided tissue regeneration by using membrane barriers and bone grafting materials has been extensively investigated in periodontal regenerative therapy to induce new attachment of periodontium damaged by periodontal disease [8]. It is an accepted therapeutic modality for the treatment of lesions with furcation involvement (class I \& II) and interproximal defects [9]. It can also be used for bone regeneration following tooth extractions and reconstruction of alveolar ridges. Guided tissue regeneration, especially by using bone grafting materials, has also been widely used in implant dentistry to enhance new bone formation for placement of implants. Studies have reported success in using barriers to augment bone prior to or after implant placement [10]. Guided bone regeneration (GBR) techniques have been successfully applied in the treatment of peri-implant bone defects and for increasing the width and height of the alveolar ridge in experimental animals and in humans [11].

Biomaterial is a nonviable material used in medicine and dentistry intended for interaction with biological systems. Any material introduced into the human organism, such as GTR membranes, has to fulfill two important requirements: safety and efficacy. Safety is assessed through a wide selection of in vitro and in vivo assays for testing specific aspects of biocompatibility. Cell culture cytotoxicity, subcutaneous implantation, blood compatibility, hemolysis, carcinogenesis, mutagenicity, pyrogenicity, short- and long-term histological tissue reaction are some of the assays used to evaluate biocompatibility. Characteristics for GTR membranes have been described by several authors. They include biocompatibility, cell exclusion, space maintenance, tissue integration and ease of use [12] (Table 1).

\section{Table 1: Essential Design Criteria for Guided Tissue Regeneration Membranes}

1. Tissue integration: An open microstructure to encourage
tissue integration and limit epithelial migration, while
creating a stable site for wound healing.
2. Cell occlusivity: Separate all cell types so that the
desired cells can repopulate the defect area.
Clinical manageability: Easy to cut and shape to fit
particular periodontal defects.
Space provision: Resist collapse from the pressure of
overlying tissue so that they can maintain adequate space
during the healing period.
Biocompatibility: Non-toxic, non-antigenic and induce
minimal inflammatory response from the host.
Membrane stability: Remain in situ to allow progenitor
cells adequate time to repopulate the defect site without
interference from gingival connective tissue or epithelium.
Membrane resorption: Be degraded, replaced, or
incorporated into the healing flap after cell selection is
complete.

(Adapted from Reference no. [12]).

Membrane can be non-resorbable and resorbable (Table 2) [1].

\section{Nonresorbable Membranes}

Nonresorbable membranes retain their build and form in the tissues, requiring a second surgical procedure for removal, thus adding to the trauma of the periodontal tissues and to patient discomfort, as well as raising the costs and duration of therapy. Many materials have been used as nonresorbable barriers for GTR including bacterial (Millipore, Billerica, MA) filters and a rubber dam, but the most commonly used material is the ePTFE membrane. The first case report evaluating GTR as a therapy used a Millipore filter as a barrier membrane to regenerate the periodontium in a 9-mm defect on a hopeless tooth [12]. Nonresorbable membranes have been used to treat furcation involvement as well, although with more variable success.

PTFE is a fluorocarbon polymer with exceptional inertness and biocompatibility, prevents tissue ingrowth 
Table 2: List of Commercially Available Membranes for GTR/GBR Applications

\begin{tabular}{|c|c|c|c|}
\hline Resorbability & Commercial name & Composition & Degradation rate \\
\hline \multirow[t]{2}{*}{ Non-resorbable } & Cytoplast $\circledast$ TXT-200 & $\begin{array}{c}\text { High-density } \\
\text { polytetrafluoroethylene(d-PTFE) }\end{array}$ & Non-degradable $\AA$ \\
\hline & Cytoplast $\circledast$ Ti-250 & $\begin{array}{c}\text { Titanium-reinforced high-density } \\
\text { PTFE }\end{array}$ & Non-degradable $\AA$ \\
\hline \multirow[t]{3}{*}{ Resorbable synthetic } & Resolut LT® & Poly-dl-lactic/co-glycolic acid & 5-6 months \\
\hline & Vicryl $\AA^{\circledR}$ & $\begin{array}{c}\text { Polyglactin } 910 \\
\text { Polyglycolide/polylactide }(9: 1, \mathrm{w} / \mathrm{w})\end{array}$ & $\sim 9$ months \\
\hline & Atrisorb® & $\begin{array}{l}\text { Poly-dl-lactide and solvent (N-methyl- } \\
\text { 2-pyrrolidone) }\end{array}$ & $6-12$ months \\
\hline \multirow[t]{4}{*}{$\begin{array}{c}\text { Resorbable } \\
\text { collagen-based }\end{array}$} & AlloDerm ${ }^{\circledR}$ & $\begin{array}{l}\text { Collagen Type-I derived from } \\
\text { cadaveric human skin }\end{array}$ & $\sim 16$ weeks \\
\hline & Bio-Gide® & $\begin{array}{l}\text { Collagen derived from porcine skin } \\
\text { (Types I and III) }\end{array}$ & 24 weeks \\
\hline & BioMend Extend $\AA$ & $\begin{array}{c}\text { Collagen Type-I derived from bovine } \\
\text { tendon }\end{array}$ & 18 weeks \\
\hline & Cytoplast $\circledast$ RTM & $\begin{array}{l}\text { Collagen Type-I derived from bovine } \\
\text { tendon }\end{array}$ & 26-38 weeks \\
\hline
\end{tabular}

Cytoplast $\AA^{(O s t e o g e n i c s ~ B i o m e d i c a l, ~ L u b b o c k, ~ T X, ~ U S A) ; ~ R e s o l u t ~ L T ® ~(W . L . ~ G o r e ~ \& ~ A s s o c i a t e s ~ R e g e n e r a t i v e ~ T e c h n o l o g i e s, ~ N e w a r k, ~ D E, ~ U S A) ; ~ V i c r y l ® ~(E t h i c o n ~}$ Inc., Somerville, NJ, USA); Atrisorb® (Atrix Laboratories Inc., Fort Collins, CO, USA); AlloDerm ${ }^{\circledR}$ (LifeCell, Branchburg, NJ, USA); Bio-Gide® (Osteohealth, Shirley, NY, USA); BioMend Extend® (Zimmer Dental Inc., Warsaw, IN, USA).

(Adapted from Refrence no. [1]).

and does not elicit foreign-body response after implantation, but is nonporous. Membrane insertion can cause minor complications such as pain, purulence and swelling, with an incidence somewhat higher than that reported for conventional periodontal surgery.

\section{Bioresorbable Membranes}

Resorbable membranes do not require additional surgery, reduce patient discomfort and costs, and eliminate potential surgical complications. By their inherent nature, absorbable membranes disintegration is not possible to control. The disintegration starts immediately upon placement in the surgical site, and speed can vary considerably amongst individuals, particularly for materials requiring enzymatic degradation like collagen. Bioabsorbable membranes are composed of a wide variety of materials including collagen, polylactic acid, polyurethane, polyglactin-910, acellular dermal matrix, dura mater, chitosan, periosteum, and calcium sulfate. The most common material is collagen, which can be modified through various collagen cross-linking processing techniques to vary the resorption rate.

\section{Natural Materials}

Collagen has been used in medicine and dentistry because of its biocompatibility and improvement of healing. Collagen has many auspicious biological activities: it has low immunogenicity is hemostatic, attracts and activates periodontal ligament and ginigival fibroblast cells, potentially augments tissue thickness. During wound healing interactions between collagen and various cell types take place. Collagen is acquired from animal skin, tendons or intestines. After isolation and purification by means of enzymatic preparation or chemical extraction, it is further processed to various forms. The most common chemical modification is crosslinking, usually aldehyde treatment, resulting in reduced water absorption, decreased solubility and increased tensile strentgth. Studies suggest that collagen membrane barrier is well tolerated by the host, does not induce an inflammatory response, or delay healing, and improves clinical parameters during the treatment of intrabony defects [13]. Other natural products tested for GTR with success are Platelet Rich Fibrin (PRF), dura mater, oxydized cellulose, Platelet rich plasma, amniotic membrane, egg shell membrane, periosteum and laminar bone.

PRF is a new step in the platelet gel therapeutic concept with simplified processing minus artificial biochemical modification which accelerates healing at surgical sites, serving as a beneficial ingredient for regeneration. Choukran Platelet Rich Fibrin, a second generation platelet concentrate is defined as an autologous leukocyte, cellular and fibrin matrix. It consists of an assembly of cytokines, glycanic chains 
and structural glycoproteins enmeshed between a slowly polymerized fibrin network [14]. Beneficial effects of PRF have been studied in various procedures such a facial plastic surgery, sinus lift procedure, as sole osteoconductive filling material and for multiple gingival recessions [15].

According to Simon Pieri et al. the use of PRF and bone grafts offers the following four advantages: First, the fibrin clot plays an important mechanical role, with the PRF membrane maintaining and protecting the grafted biomaterials and PRF fragments serving as biological connectors between bone particles. Second, the integration of this fibrin network into the regenerative site facilitates cellular migration, particularly for endothelial cells necessary for the neoangiogenesis, vascularization and survival of the graft. Third, the platelet cytokines (PDGF, TGF- $\beta$, IGF-1) are gradually released as the fibrin matrix is resorbed, thus creating a perpetual process of healing. Lastly, the presence of leukocytes and cytokines in the fibrin network can play a significant role in the self-regulation of inflammation within the grafted material [16].

Another recently introduced material - Chitosan is a biocompatible natural biopolymer that is a copolymer of $\mathrm{N}$-acetyl- glucosamine and $\mathrm{N}$-glucosamine units. It is acquired from chitin by depolymerization and partial deacetylation. Due to its various biological characteristics, chitosan has been widely investigated as a bone substitution material and a membrane material in orthopedic and periodontal applications. The introduction of nanotechnology has improved the properties of various kinds of fibers. Polymer nanofibers, with diameters in the nanometer range, possess a larger surface area per unit mass and permit an easier addition of surface functionalities compared to polymer microfibers [17].

\section{Synthetic Materials}

Synthetic resorbable materials are usually organic aliphatic thermoplastic polymers. The materials most commonly used are poly-a-hydroxy acids, which include polylactic polyglycolic acid and their copolymers. One of the advantages of polyhydroxy acid is hydrolysis to final products water and carbon dioxide. Degradation time can vary, lengthened through the addition of lactides or glycols. Besides the already mentioned polyester membranes, use of polyurethane for membrane production has been tested as well. Polyurethanes are organic polymers containing urethane group - $\mathrm{NH}-\mathrm{CO}-\mathrm{O}-$, materials with diverse properties. Polyether urethanes are degraded through enzymatic and oxidative degradation. Animal experiments showed that polyurethane membranes tend to swell, and inflammation at the flap margins and recession were more pronounced than in polylactic membranes. The membrane seems to be present in the tissue for at least 8 weeks after implantation [18].

\section{CASE REPORT}

The clinical report demonstrates the use of PRF used as a membrane to cover an intrabony defect and showed significant improvement in clinical as well as radiographic parameters after 3 months of healing.

A 47 year old female patient reported to the Department of Periodontics and Implantology complaining of pain in the lower left mandibular molar region. Patient did not give any relevant medical history and there was no systemic condition that could interfere with physiologic wound healing. On intraoral examination there was generalized bleeding on probing present but no swelling and no pus exudation. The probing pocket depth on mesiobuccal aspect of 36 was $6 \mathrm{~mm}$ while on the distobuccal aspect and distolingual aspect it was $9 \mathrm{~mm}$ and $12 \mathrm{~mm}$ respectively. A periapical radiograph was taken using the standardized techniques which revealed the presence of interproximal intrabony defects irt to tooth 36 . Oral hygiene instructions and motivation of the patient in performing effective oral hygiene measures were given. Non surgical periodontal therapy by means of conventional scaling and root planning using curettes and ultrasonic instruments was done. Patient was recalled after one week and surgical periodontal therapy was performed. A full thickness flap was raised from the distal aspect of 34 to distal aspect of 37 . A two-wall vertical defect on the distal root with furcation involvement was observed irt $36.10 \mathrm{ml}$ of patients blood was obtained and centrifuged at 3000rpm for 10 mins to obtain PRF which was squeezed between a sterile gauge piece to obtain a membrane (Figures 13). Open flap debridement was performed (Figure 4) and following the placement of bone graft (Figure 5) into the defect area a PRF membrane was placed (Figures 6 and 7). The mucoperiosteal flap was repositioned and secured in place using 3-0 nonabsorbable black silk surgical suture (Figure 8). The surgical area was protected and covered with periodontal dressing (Figure 9). Periodontal dressing and sutures were removed one week post-operatively. Patient was re-instructed for proper oral hygiene measures postoperatively and was recalled for followup at 1 month and 3 months thereafter. 


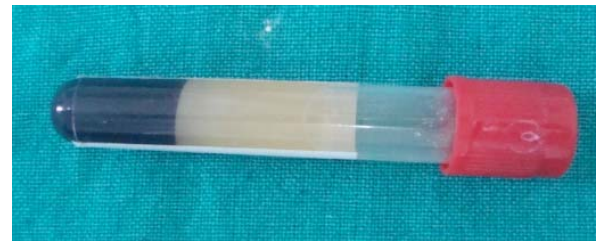

Figure 1: Post Centrifugation of Blood (PRF with Red blood cell sediment).

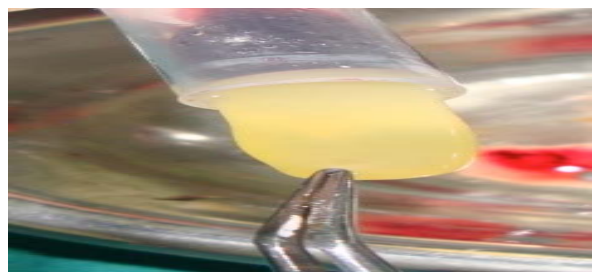

Figure 2: PRF being separated.

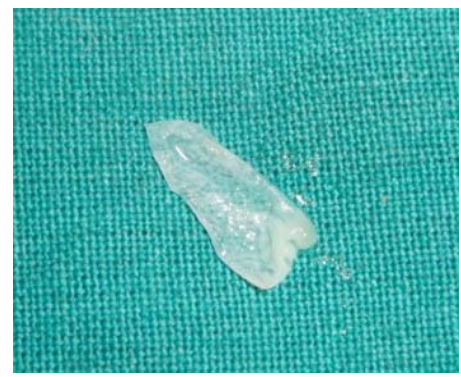

Figure 3: PRF membrane obtained after squeezing between gauge piece.

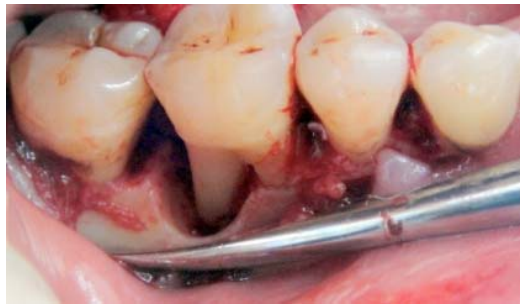

Figure 4: Intra bony defect.

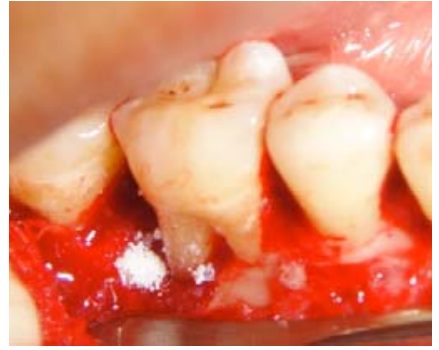

Figure 5: Bone graft palced into defect.

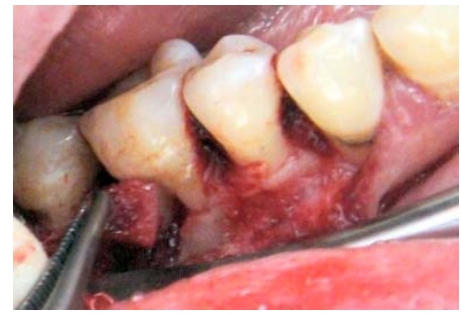

Figure 6: PRF membrane placed over bone graft.

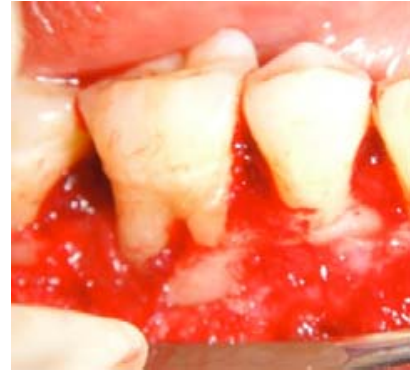

Figure 7: PRF covering defect.

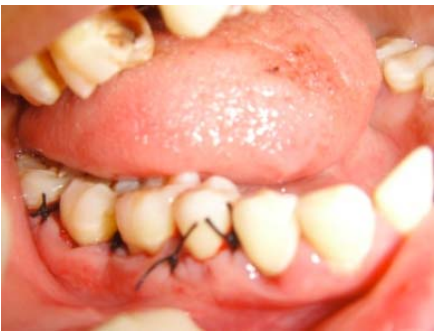

Figure 8: Sutures placed.

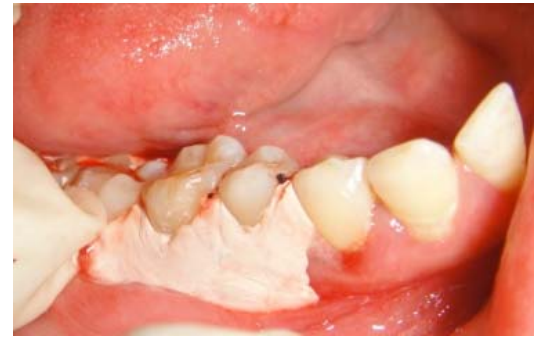

Figure 9: Coe-pack placed.

Re-examination at 3 months after the periodontal surgery revealed a 4-5 $\mathrm{mm}$ bone gain and bone fill on comparing with pre-operative radiograph (Figures 10, 11) and clinical probing on the distobuccal aspects of 36 with no sign of bleeding from sulcus.

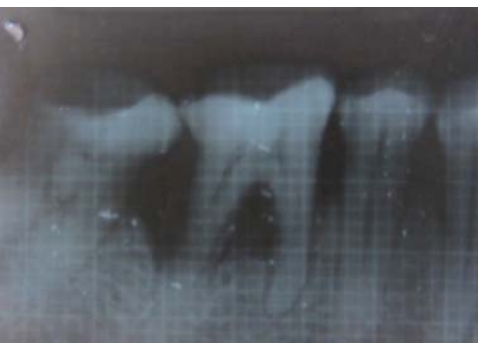

Figure 10: Pre-operative radiograph.

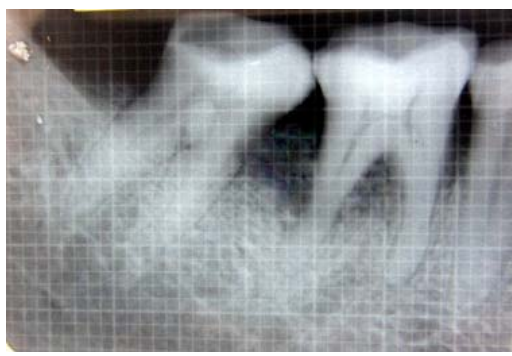

Figure 11: Post-operative radiograph. 


\section{CONCLUSION}

The use of GTR membranes can lead to significant periodontal regeneration, and formation of cementum with inserting fibers, although complete regeneration has never been reported. The present study demonstrated the clinical efficacy of PRF in the treatment of intrabony defect and showed significant improvement in clinical as well as radiographic parameters. PRF acts as a healing and interposition biomaterial.

Because it is a simplified, easy, fast and cost effective preparation without use of any anti-coagulant, along with functional intact platelet in fibrin matrix and substantial release of growth factors PRF is considered the leader in fibrin techonology. PRF along with bone grafting have shown to be an effective modality of therapy in the regenerative treatment of a osseous defects. Further investigations are needed to improve clinical outcome, because there is insufficient proof of the clinical efficacy of current concepts. Better understanding of factors influencing regenerative procedure will probably improve predictability of therapy of bone defects around natural teeth and implants.

\section{REFERENCES}

[1] Bottino MC, Thomas V, Schmidt G, Vohra YK, Chu TMJ, Kowolik MJ, et al. Recent advances in the development of GTR/GBR membranes for periodontal regeneration-A materials perspective. Dental Materials 2012; 28: 703-21. http://dx.doi.org/10.1016/j.dental.2012.04.022

[2] Lafzi A, Farahani RMZ, Shoja MM, Tubbs RS. Amniotic membrane: A potential candidate for periodontal guided tissue regeneration? Medical Hypotheses 2007; 69: 454-73. http://dx.doi.org/10.1016/j.mehy.2006.12.022

[3] Dangaria SJ, Itov Y, Luan X, Diekwisch TGH. Successful Periodontal Ligament Regeneration by Periodontal Progenitor Preseeding on Natural Tooth Root Surfaces. Stem Cells Development 2011; 20(10). http://dx.doi.org/10.1089/scd.2010.0431

[4] Parrish LC, Miyamoto T, Fong N, Mattson JS, Cerutis DR. Non-bioabsorbable vs. bioabsorbable membrane: assessment of their clinical efficacy in guided tissue regeneration technique. A systematic review. J Oral Sci 2009; 51(3): 383-400.

http://dx.doi.org/10.2334/josnusd.51.383

[5] Holtzclaw DJ, Toscano NJ. Amnion Chorion allograft barrier used for guided tissue regeneration treatment of periodontal intrabony defects: a retrospective observational report. Clin Adv Periodontics 2012.

http://dx.doi10.1902/cap.2012.110110

[6] Gager AH, Schultzf AJ. Treatment of Periodontal Defects with an Absorbable Membrane (Polyglactin 910) With and Without Osseous Grafting: Case Reports. J Periodontal 1991; 62: 276-83.

http://dx.doi.org/10.1902/jop.1991.62.4.276

[7] Bashutski JD, Wang HL. Periodontal and Endodontic Regeneration. J Endod 2009; 35: 321-28. http://dx.doi.org/10.1016/j.joen.2008.11.023

[8] Lin L, MYH, Ricuccim D, Rosenberg PA. Guided Tissue Regeneration in Periapical Surgery. J Endod 2010; 36: 61825

http://dx.doi.org/10.1016/j.joen.2009.12.012

[9] Markman C, Fracalanzza CEL, Novaes AB. Slow Release of Tetracycline Hydrochloride From a Cellulose Membrane Used in Guided Tissue Regeneration. Periodontol 1995; 66: 978-83.

http://dx.doi.org/10.1902/jop.1995.66.11.978

[10] Bunyaratavej P, Wang HL. Collagen Membranes: A Review. J Periodontol 2009; 72: 215-29. http://dx.doi.org/10.1902/jop.2001.72.2.215

[11] Simion M, Scarano A, Gionso L, Piattelli A. Guided Bone Regeneration Using Resorbable and Nonresorbable Membranes: A Comparative Histologic Study in Humans. JOMI 1996 on CD-ROM: 735-742.

[12] Lin N-H, Gronthos S, Bartold PM. Stem cells and periodontal regeneration. Aust Dental J 2008; 53: 108-21. http://dx.doi.org/10.1111/j.1834-7819.2008.00019.x

[13] Mattson JS, McLey LL, Jabro MH. Treatment of Intrabony Defects With Collagen Membrane Barriers. Case Reports. J Periodontol 1995; 66: 635-45. http://dx.doi.org/10.1902/jop.1995.66.7.635

[14] Inchingolo F, Tatullo M, Marrelli M, Inchingolo AM, Scacco S Inchingolo $A D$, et al. Trial with Platelet-Rich Fibrin and BioOss used as grafting materials in the treatment of the severe maxillar bone atrophy: clinical and radiological evaluations. Eur Rev Med Pharmacol Sci 2010; 14(12): 1075-84.

[15] Chen FM, Zhang J, Zhang M, An Y, Chen F, Wu ZF. A review on endogenous regeneration techonology in periodontal regeneration medicine. Biomaterials 2010; 31(31): 7892-27.

http://dx.doi.org/10.1016/j.biomaterials.2010.07.019

[16] Aroca S, Keglevich T, Barbieri B, et al. Clinical evaluation of a modified coronally advanced flap alone or in combination with a platelet rich fibrin membrane for the treatment of adjacent flap alone or in combination with platelet rich fibrin membrane for the treatment of adjacent multiple gingival recessions: A 6 month study. J Periodontol 2009; 80: 244-52. http://dx.doi.org/10.1902/jop.2009.080253

[17] Shin SY, Park HN, Kim KH, Lee MH, Choi YS, Park YJ, et al. Biological Evaluation of Chitosan Nanofiber Membrane for Guided Bone Regeneration. J Periodontol 2005; 76: 177884.

[18] Aurer A, Srdjak KJ. Membranes for Periodontal Regeneration. Acta Stomatol Croat 2005; 39: 1-5. 